\title{
European Psychologist
}

Official Organ of the European Federation of Psychologists' Associations (EFPA) 
Politi, E., Lüders, A., Sankaran, S., Anderson, J., van Assche, J., Spiritus-Beerden, E., Roblain, A., Phalet, K., Dreluyn, I., \& Green, E.G.T. (2021). The impact of COVID-19 on the majority population, ethno-racial minorities, and immigrants: A systematic review on threat appraisals from an inter-group perspective. European Psychologist, 26(4). https://doi.org/10.1027/1016-9040/a000460

The impact of COVID-19 on majority and ethno-cultural immigrant minority populations: A systematic literature review on threat appraisals from an intergroup perspective

Emanuele Politi ${ }^{1,2}$ Adrian Lüders ${ }^{3}$, Sindhuja Sankaran ${ }^{4}$, Joel Anderson ${ }^{5}$, Jasper Van Assche ${ }^{1,6}$, Eva Spiritus-Beerden ${ }^{7}$, Antoine Roblain ${ }^{8}$, Karen Phalet $^{1}$, Ilse Derluyn ${ }^{7}$, An Verelst $^{7}$, and Eva G.T. Green ${ }^{2}$

${ }^{1}$ Center for Social and Cultural Psychology, KU Leuven, Belgium

${ }^{2}$ Social Psychology Lab, University of Lausanne, Switzerland

${ }^{3}$ Center for Social Issues Research, University of Limerick, Ireland

${ }^{4}$ Center for Social Cognitive Studies, Jagiellonian University Krakow, Poland

${ }^{5}$ School of Behavioral and Health Sciences, Australian Catholic University, Australia

${ }^{6}$ Department of Developmental, Personality, and Social Psychology, Ghent University, Belgium

7 Department of Social Work and Social Pedagogy, Ghent University, Belgium

${ }^{8}$ Center for Social and Cultural Psychology, Université Libre de Bruxelles, Belgium

\section{Corresponding author}

Emanuele Politi (https://orcid.org/0000-0002-8577-3197), Center for Social and Cultural Psychology, Faculty of Psychology \& Educational Sciences, KU Leuven, Belgium.

Tiensestraat 102 B, 3000. Leuven. E-mail: emanuele.politi@kuleuven.be.

\section{Author note}

This research was supported by a Early Postdoctoral Mobility grant from the Swiss National Science Foundation awarded to Emanuele Politi (P2LAP1_L877Og)

\section{Keywords}

COVID-19, threat appraisals, inter-group conflict, prosociality, ethno-racial and immigrant minorities 


\begin{abstract}
The COVID-19 pandemic constitutes an unprecedented threat for individuals and societies, revealing stark inequalities in preparedness, exposure, and consequences. The present systematic literature review complements extant knowledge on disasters and pandemic diseases with programmatic research on the COVID-19 pandemic. Building upon an integrative definition of threat, we merge intra-personal threat regulation with group dynamics and inter-group relations. Via streamlined methods of knowledge synthesis, we first map out a broad taxonomy of threats, as appraised by the majority population and ethnoracial and immigrant minorities. Second, we delve into research linking threat appraisals with either conflict or prosociality within and across group boundaries. To conclude, we propose some guidelines for researchers to actively involve ethno-racial and immigrant minorities, and for societies to cope cohesively with the impact of COVID-19.
\end{abstract}


Outbreaks of diseases are an inevitable aspect of human history, yet the COVID-19 outbreak constitutes an unprecedented global threat (ECDC, 2020). During this pandemic, ethno-racial and immigrant minorities disproportionately bore the brunt of the infection, experiencing cumulative stressors that were piled upon preexisting disadvantages and social exclusions (e.g., Abedi et al., 2020; see also WHO, 2020). Some of these stressors may stemm from integration challenges and restricted resources among newly arrived immigrants (Martiniello \& Rea, 2014), whereas other stressors arise from long lasting experiences of structural racism (Sears et al., 2000).

To establish the psychological impact of this global pandemic and to design inclusive recovery plans, it is crucial to consider different social ecologies in which individuals are embedded. In the present work we develop an integrative approach, contextualizing the unequal psychological impact of the pandemic on ethno-racial and immigrant minorities, as compared to the majority population. We conceptualize this impact at multiple levels of threat and discuss how these threats may impact intra- and inter-group outcomes.

Social psychological research on threat experiences is largely fragmented and comprises disconnected theoretical frameworks. Researchers have studied threat from an intrapersonal perspective as an outcome of basic cognitive and affective processes that catalyze threat cues into avoidance and approach-based reactions (e.g., Jonas et al., 2014). From an alternate social identity approach of the self, researchers have focused on how individual threat perceptions emerge from feelings of belonging to social categories or groups (e.g., Branscombe et al., 1999). Finally, researchers have examined how 'realistic' and 'symbolic' conflict are rooted in socio-structural power asymmetries between groups, thus engendering perceived threats to group cohesion and survival (Stephan et al., 2009).

Our systematic literature review incorporates these different levels of analysis and defines threat as external or internal stressors that are appraised as a potential danger to 
physical or psychological goals relevant to the personal or social self, group cohesion, and survival. We deem imperative to operationalize "threat" at different levels to provide a more contextual and comprehensive understanding of how people navigate the COVID-19 outbreak (see Doise, 1986 for an exhaustive introduction on the levels of analysis in social psychology). Our systematic review thus expands the knowledge on COVID-19 related threats and is organized in three parts: First, we tease apart different levels and sources of threat as it is appraised by members of the majority population. Second, we identify common and distinct sources and appraisals of threat among ethno-racial and immigrant minority groups. Third, we outline the social-psychological processes connecting different threat appraisals with either conflict or prosociality within and across group boundaries.

\section{Method}

We conducted a systematic literature search to identify published peer-reviewed and unpublished (i.e., pre-prints) records presenting data with content-specific information on threat appraisals related to previous disasters, pandemic diseases, and the current COVID-19 outbreak. We based our search on the Cochrane methodology and presented methods and findings following the PRISMA standard for Preferred Reporting Items for Systematic Reviews and Meta-Analyses (Moher et al., 2009); To ensure we collected such data at (a) the individual level of threat (i.e., personal and social self), (b) the collective level of threat (i.e., group cohesion and survival), and (c) intra- and inter-group outcomes (i.e., prosociality and conflict), we designed and implemented the three search strategies presented in Table 1. Each strategy comprised a common threat context and a unique concept relevant to the search, and these were combined using the Boolean operator AND. The concepts themselves comprised a series of search terms which were combined using the Boolean operator OR. Main database 
searching was conducted on November-December 2020 (PsyINFO), ${ }^{1}$ and additional unpublished literature on COVID-19 was screened on April-May 2021 (PsyArXiv).

\section{(TABLE 1 ABOUT HERE)}

\section{Study Selection and Inclusion Criteria}

Records identified by the search strategy were subjected to the first phase of screening via Abstracker (Rathbone et al., 2015), using an automated, streamlined method of knowledge synthesis (Tricco et al., 2017). In the second phase, eligibility was further assessed based on the full text of each record. We excluded records that did not focus on threat contexts relevant to this review, as well as short commentaries and editorial notes. We also excluded records that did not asses specific threat appraisal contents. For instance, generalized measures of trait anxiety, wellbeing, and stress inventories were not retained. Similarly, we excluded records measuring perceptions, opinions, and attitudes (e.g., trust in institutions, perceived personal risk) that were not explicitly and directly linked with threat appraisals (e.g., worries about freedom loss or fear of infection). The search was restricted to peer-reviewed journal articles written in English and published from the year 2000 onwards.

\section{Data Synthesis}

Data were extracted onto a spreadsheet and organized based on the following columns: (i)The national context of the threat, (ii) a focus on ethno-racial or immigrant minorities (iii), publication status (iv), specific subdimensions of threat assessment (v), relevance to intra- and inter-group outcomes (see Table S.1 in the Electronic Supplementary Materials, ESM). We used the principles of thematic analysis to code specific threat appraisals into eight distinct types of threat. The first four threat types were reported by both majority and ethno-racial and immigrant minorities, namely 1) life threat, 2) basic

\footnotetext{
${ }^{1}$ A second screening on PsycINFO was repeated on April-May 2021 to include additional references and update the literature search.
} 
psychological needs frustration, 3) livelihood and financial concerns, and 4) social disintegration and political dysregulation. The last four threat types were uniquely reported by ethno-racial and immigrant minorities, namely 5) stigma and discrimination, 6) stress sensitization, 7) legal vulnerability, and 8) marginalization.

\section{Results}

Our search for data based on our broad conceptualization of threat identified 5,064 relevant records. After excluding 4,595 non-relevant articles, we retained 468 studies: 167 directly relevant empirical studies on past disasters and pandemics, 292 directly relevant empirical studies on the current COVID-19 outbreak, and 8 systematic reviews and one metaanalysis that linked past pandemics and the current COVID-19 outbreak (see Figure 1). Systematic reviews or meta-analyses were screened first, followed by the thematic grouping of empirical studies based on shared content or similarities in findings.

Findings were organized by theoretical account wherein we reviewed evidence from previous disasters and infectious diseases for each account before introducing research assessing threat in the context of the COVID-19 pandemic. The literature presented below is summarized in prose. However, Supplementary Table S1 in ESM presents the full collated and synthesized data from this systematic review.

\section{(FIGURE 1 ABOUT HERE)}

\section{Threat Appraisals by the Majority Population}

Among the total records selected, 392 out of 468 empirical papers (83.8\%), eight systematic reviews, and one meta-analysis focused on perspectives from the majority population. Both the systematic reviews and the meta-analysis reviewed prior evidence about the negative consequences of social isolation (e.g., Hossain et al., 2020) and more general “Coronaphobia” for individual distress and mental health (e.g., Şimşir et al., 2021). The empirical papers were organized around four main threat types on the basis of the specific 
contents of threat appraisals, from personal and social self to group cohesion and survival as operationally defined earlier (Figure 2).

Life threat. Extremely adverse events, such as natural disasters and pandemic outbreaks, trigger immediate fears and long-term anxieties about the health ramifications of disaster exposure (Coelho et al., 2020). Relatedly, life threat triggers severe anxiety due to awareness by individuals that their death is inevitable (Jonas et al., 2014).

Among the 392 empirical studies with the majority population, $260(66.3 \%)$ focused on life threats following disasters and disease outbreaks. Terrorism-related threats like the 2011 Oslo bombing were observed in 30 papers (e.g., Heir et al., 2016). Threats of natural disasters, like among adolescents exposed to the 2010 earthquake in Chile, were seen in 16 papers (e.g., Guerra et al., 2014). Seventeen papers explored threats of infectious diseases, like Ugandan midwives endangered by HIV (Salyer et al., 2008). Life threat experienced in response to the COVD-19 outbreak received extensive attention $(n=197)$, as reflected by a multitude of scales measuring fear and distress of getting seek and dying because of the coronavirus (e.g., Ahorsu et al., 2020; Feng et al., 2020; Taylor et al., 2020).

Basic psychological needs frustration. The COVID-19 pandemic and the enforced countermeasures may hamper psychological well-being by preventing individuals from pursuing specific goals related to basic psychological needs for competence, autonomy, and social relatedness (Ryan \& Deci, 2000). Consequently, people may experience goal blockage or personal goal frustration, which may increase their psychological vulnerabilities (Vansteenkiste \& Ryan, 2013).

Among the 392 empirical studies with the majority population, 74 (18.9\%) focused on basic psychological needs frustration following disasters and disease outbreaks. These threats were observed in four papers on terrorism, like among Israeli settlers in Palestinian territories (Shalev, 2006); four papers on natural disasters, like among young adults affected by the 
Canterbury earthquakes in New Zealand (Fergusson et al., 2015); and two papers on infectious diseases, like among veterans with HIV in the US (Greysen et al., 2013). In comparison to previous literature on this topic, basic psychological need frustration received more attention in response to the COVID-19 outbreak $(n=59)$, with studies focusing specifically on fear of uncertainty (e.g., Arpaci et al., 2020), lack of control (e.g., Irshad et al., 2020), and social isolation (e.g., Kira, Shuwiekh, Rice et al., 2020).

Livelihood and financial concerns. Dealing with an actual or perceived scarcity of resources is demanding and may impede optimal cognitive functioning (e.g., Mani et al., 2013). Empirical research demonstrates that resource scarcity impairs decision-making, and depletes executive control functions (Mullainathan \& Shafir, 2014). Hence, there is a clear need for humans to have a livelihood, earn an income, and to support themselves and their family.

Among the 392 empirical studies with the majority population, 65 (16.6\%) focused on livelihood and financial concerns following disasters and disease outbreaks. These threats were observed in three papers on terrorism, such as in the aftermath of the $9 / 11$ attack in the US (Brown et al., 2019); and six papers on natural disasters, e.g., among survivors of the 2008 Kosi River flooding in India (Crabtree, 2013). Livelihood and financial concerns received considerable attention in response to the COVID-19 outbreak $(n=56)$, not only at the individual level, like impaired socio-economic conditions (e.g., Mertens et al., 2021) and job loss (e.g., Rogers et al., 2021), but also at the collective level, related to supply shortages (e.g., Arpaci et al., 2020) and global financial crisis (e.g., Kachanoff et al., 2020).

Social disintegration and political dysregulation. Durkheim (1897/1987) first conceptualized anomie as a societal situation in which both the political and the moral norm systems lose power to regulate society. Based on his seminal work, Teymoori et al. (2017) proposed a psychological approach to understanding anomie, which was closer to the concept 
of threat and included the perception of an irreparable breakdown of social cohesion (i.e., social disintegration) and delegitimation of political leadership (i.e., political dysregulation).

Among the 392 empirical studies with the majority population, political disintegration was never appraised as a threat, but was approached indirectly, by measuring political and institutional distrust. However, 25 papers $(6.4 \%)$ focused explicitly on threats of social disintegration. This threat was observed in five papers on terrorism, like among residents of the small Finnish community of Jokela after the 2008 shootings (Vuori, 2016); and three papers on natural disasters, e.g., among fisherman villagers after the 1989 Exxon Valdez oil spill in Alaska (Ritchie, 2012). Social disintegration threat was not observed in relation to other infectious diseases. Yet, a number of studies focused on social disintegration in response to the COVID-19 outbreak ( $n=17)$, in particular fears of people's irresponsibility (e.g., Arpaci et al., 2020) and loss of national values (e.g., Kachanoff et al., 2020).

\section{(FIGURE 2 ABOUT HERE)}

\section{Threats Appraised by Ethno-racial and Immigrant Minorities}

Among the total records selected, 66 out of 468 empirical papers (14.1\%) examined threat types experienced by ethno-racial and immigrant minority members. No systematic literature reviews or meta-analyses were found instead. The review by Zeppegno et al., (2020) was an exception wherein they provided an exhaustive overview of the burden the pandemic poses on vulnerable "outgroups", like international migrant workers and homeless people.

A closer look at the empirical papers including ethno-racial or immigrant minorities revealed that, 36 empirical papers compared the experiences of majority White with distinct experiences of African Americans $(n=5)$, other ethno-racial minorities (e.g., Latinos, Asians, and Arab Muslims, $n=21$ ), or immigrants without host national citizenship ( $n=10)$. Results generally converged on showing that ethno-racial and immigrant minorities are at high risk of 
experiencing all general types of threats (e.g., Anderson-Carpenter \& Neal, 2021), like life threat $(n=14)$, basic psychological needs frustration $(n=7)$, and livelihood and financial concerns $(n=6)$. The remaining 30 empirical papers focused on ethno-racial or immigrant minorities, such as African Americans $(n=4)$, other ethno-racial minorities $(n=12)$, and immigrants $(n=14)$. Results showed that these groups experience additional specific threats that are not reported by the national/White majority population. We grouped these additional threats among ethno-racial and immigrant minorities around four main threat types, ranging from most to least commonly reported threat appraisals (Figure 2).

Stigmatization and discrimination. Stigmatization and discrimination against ethno-racial and immigrant minorities convey social identity threats leading to a range of negative psychological outcomes (e.g., Major \& O’Brien, 2005). As a result, emergencies and their aftermath give rise to conditions under which stigmatization and discrimination against ethno-racial and immigrant minorities are heightened (e.g., Demirtaş-Madran, 2020).

Among the 67 empirical studies focusing on ethno-racial and immigrant minorities, $50.7 \%(n=34)$ assessed stigmatization and discrimination. These threats were observed in 13 papers on terrorism, e.g., among recent immigrants in Canada after the 9/11 attacks (Rousseau et al., 2011); three papers on natural disasters, e.g., among Black American Katrina survivors in New Orleans (Chen et al., 2007); and five papers on previous infectious diseases, e.g., among people of Caribbean descent in the Netherlands (Stutterheim et al., 2011). Similarly, stigma and discrimination were observed in 13 papers about the COVID-19 outbreak, e.g., among Asian Americans and Asian immigrants in the US (Wu et al., 2021).

Stress sensitization. Prior exposure to traumatic life events involves regulatory feedback mechanisms that can negatively impact stress reactivity system functioning; a process that has been termed stress sensitization (McFarlane, 2010). Stress sensitization 
enhances perceptions of threat and reinforces negative interpretations of new stressful situations (e.g., Dougall et al., 2000).

Given the migration perils, discrimination, and post-traumatic stress experienced by certain ethno-racial and immigrant minorities, these groups may be particularly sensitive to catastrophic events. Among the 67 papers that included ethno-racial and immigrant minority perspectives, 4 (6\%) focused on stress sensitization. This threat was observed in one paper on terrorism, namely among refugees in the US exposed to the extensive media coverage of the 9/11 attacks (Kinzie, 2008); and in two papers on natural disasters, e.g., for non-EU immigrants in the aftermath of the Enschede Firework Disaster in the Netherlands (Smid et al., 2018). Stress sensitization threat was not observed in relation to other infectious diseases. Yet, one empirical paper on COVID-19 reported that collective identity trauma among Arab Muslims from many Middle Eastern countries reinforced the effect of COVID-19 traumatic stress on death anxieties and lowered well-being (Kira, Shuwiekh, Alhuwailah et al., 2020).

Legal vulnerability. Ethno-racial minorities with national citizenship and immigrants with stable residence permit are secured from legal vulnerability. Yet, uncertain legal status is a threat that migrants with temporary, expiring, or irregular residence status are often faced with (Elisabeth et al., 2020). Legal vulnerability has been known to be associated with fear, anxiety, and guilt, related to a lack of access to resources and service providers, including health services (e.g., Gonzales et al., 2013).

Among the 67 retained empirical studies that focused on ethno-racial and immigrant minorities, three analyzed legal vulnerability as a specific threat (4.5\%). This threat was observed in two papers on terrorism, e.g., asylum seekers and refugees in the US fearing arrest, detention, and deportation after the 9/11 attacks (Piwowarczyk \& Keane, 2007); and one paper on infectious diseases, namely Swedish legal immigrants being reluctant to seek medical attention and HIV-screening (Kalengayi et al., 2012). We could not find any record 
investigating legal vulnerability as a potential stressor for migrants facing the COVID-19 outbreak. Yet, fear of being reported to the immigration authorities and deported if they sought assistance may have reduced willingness among undocumented migrants to come forward for screening, contact tracing, or treatment (WHO, 2020).

Marginalization. The rift of social relations with close relatives and support networks in their home country, cultural conflicts, and perceived incompatibilities, combined with challenges to establish new relations in the receiving society, may result in isolation and acculturative stress among ethno-racial and immigrant minorities (e.g., Yako \& Biswas, 2014). By threatening social connectedness, self-worth, and identity continuity, marginalization translates into psychological strains (e.g., Marinucci \& Riva, 2020).

Limited work focused on the risks of marginalization among ethno-racial and immigrant minorities during disasters and pandemics. This threat was assessed in 2 out of 67 papers $(2.3 \%)$, in relation to terrorism and identity conflict, like among Muslim-American youth in the wake of the 9/11 attacks (Sirin \& Fine, 2007). We could not find any record investigating rupture of transnational support networks during the COVID-19 outbreak, particularly among newcomers and transit migrants. Yet, due to border closures, interruption of family reunification procedures, and travel bans, these vulnerable groups may have been cut off from all sources of social support (Politi \& Roblain, 2021).

\section{From Threat Appraisals to Intra- and inter-group Outcomes}

Disasters and pandemic threats have far-reaching societal implications. In total, we found 123 empirical papers $(26.8 \%)$ that included outcomes relating to intra- and inter-group processes. These outcomes were either conflictual or prosocial. In particular, 44 empirical papers focused on terrorism, 26 investigated the role of natural disasters, 6 were conducted in the context of past infectious diseases, and 47 were conducted in light of the COVID-19 epidemic. First, we will discuss the overall pattern of results of these studies, starting from 
conflictual and moving to prosocial intra- and inter-group outcomes. Secondly, we will highlight some additional gaps in the current state of the literature.

Conflict within and across group boundaries. In general, threat clues can breed ethnocentrism and escalate violent inter-group conflict (e.g., Oswald, 2005); they can exacerbate prejudice, discrimination and dehumanization, and spur support for authoritarian governments and policies among the majority population (e.g., Green et al., 2010). People also tend to endorse negative stereotypes of outgroups specifically in response to perceived personal threat (Asbrock \& Fritsche, 2013). Within group boundaries, external threats may result in scapegoating and ostracism of deviant ingroup members (e.g., Marques, Paez, \& Abrams, 1998). The threat, in all of its forms, thus constitutes a potent ingredient for intraand inter-group conflict (Dhanani \& Franz, 2021).

Natural disasters and pandemic diseases were often associated with increased intergroup conflict, while evidence for intra-group conflict is lacking. Increases in prejudice and discrimination against Muslim and immigrant communities have been repeatedly documented in the aftermath of terrorist attacks (e.g., Van de Vyver et al., 2016). Yet, outgroup derogation and ethnic prejudice may also spread from seemingly unconnected events, such as natural disasters and pandemics (Kim \& Chang, 2014). Negative inter-group consequences of natural disasters and pandemics stem from several possible underlying processes, such as outgroup blaming for spreading the disease (Zagefka, 2021), protection of ideological belief systems (Fairlamb \& Cinnirella, 2021), or perceived competition for restricted resources (Vezzali et al., 2018).

Applied to the COVD-19 pandemic, anti-Asian prejudice triggered stigmatization of Asian people and other minority groups (Tabri et al., 2020). Also, norm deviation was used to justify outgroup derogation more than ingroup scapegoating (Van Assche et al., 2020). Relatedly, increases in the desire for national cohesion and conformity during the pandemic 
resulted in a strong rejection of sexual minorities (Golec de Zavala et al., 2020). These findings suggest that positive inter-group relations and the rights of minorities may be at risk during times of global emergences.

Prosociality within and across group boundaries. Threat avoidance mechanisms that promote ingroup favoritism and outgroup derogation shed a pessimistic light on intergroup relations. However, some 'silver lining' evidence suggests that threat appraisals may enhance helping behaviors. In social environments that valued prosociality and supported people's basic needs for autonomy, belonging and competence, prosociality fulfilled an adaptive threat regulation function (e.g., Jonas et al., 2014). Along those lines, post-traumatic stress was found to be attenuated via increased compassion, empathy, and altruism (Tedeschi et al., 1998).

Prosociality has been consistently observed in the face of natural disasters, like the 2012 Northern Italian earthquake (Andrighetto et al., 2016) and the 2004 Tsunami in South Asia (Van Leeuwen, 2007). Jointly facing a disaster situation creates a sense of togetherness that may translate into collective selfhood (Drury et al. 2009). Although, helping behaviors in the aftermath of emergency situations was mostly examined in light of intragroup prosociality, emerging social identities and empathic bonds with other survivors may go beyond interpersonal helping within existing social networks and thus connect people across social groups (Vollhardt \& Staub, 2011).

In the context of the COVID-19 outbreak, "bonding" types of prosociality within one's own community (e.g., when you help your neighbor with groceries), and "bridging" variants of prosociality, including vulnerable populations beyond one's immediate in-group (e.g., when you volunteer at a homeless shelter) were both connected with dispositional factors, such as fulfilment of self-transcendence goals (Politi et al., 2020). Moreover, 
outgroup helping was positively connected with contextual clues about the global emergency,

such as ingroup (instead of outgroup) blaming for the spreading of the virus (Zagefka, 2021).

\section{Discussion}

The psychological impact of disasters and pandemic diseases has commonly been assessed in terms of fears, worries and concerns. Our review, however, revealed some gaps in the literature. Firstly, future investigations should focus more on long-lasting threats and move beyond the immediate fear of virus transmission (for a similar point, see Coelho et al., 2020). Indeed, some stressors may disappear quickly when restrictions are eased and contamination is reduced, while other threats — such as economic and social disruptionsmay entail much longer periods of recovery. Moreover, most researched threats primarily focus on the individual, while collective threats to the social fabric and political arrangements need to be taken more into account. While some noticeable efforts to assess a broader variety of threats in comprehensive scales have been made (e.g., Anderson et al., 2021; Mertens et al., 2021), this literature review argues that measurements should be extended and refined to capture a broader range of possible threat appraisals. Second, the review suggests additional specific threats among ethno-racial and immigrant minorities as distinct from common threats shared with the majority population. The review thus sheds light on the unequal psychological impact of disasters on individuals and groups with different positions in the wider society and future research may unravel the processes that account for these apparent disparities in threat appraisals. Most likely, the intersectionality of unique and cumulative pre-existing and incidental stressors among ethno-racial and immigrant minorities explains their heightened sensitivity to common as well as distinct threats. Third, there is a need to differentiate more general process from specific contents of situated threats appraisals associated to ethno-racial and immigrant groups with and without host national citizenship (see Romero, 2008). 
As for intra- and inter-group outcomes, solid evidence has linked threat appraisals to both conflict and prosociality, but some caution is warranted. First, only 56 out of 123 studies $(46 \%)$ measuring intra- and inter-group outcomes directly assessed 'threat', and only 44 (35.8\%) specified the type of threat in their study. Though different sources of threat certainly lead to different outcomes, a systematic examination of these differential effects is currently lacking in the COVID-19 literature. As an exception, Nisa and colleagues found interactive effects of life threat and livelihood and economic concerns on compliance with COVID-19 mitigation measures (Nisa et al., 2021). Second, only 12 out of 123 records on processes related to intra- and inter-group outcomes (10\%) included samples of ethno-racial or immigrant minority members. As an exception, Andrighetto and colleagues found that disaster exposure was negatively associated with outgroup helping intentions among national majority members while it was positively associated with outgroup helping among immigrant minorities (Andrighetto et al., 2016). The gaps revealed by our review calls for more systematic investigation of different minority perspectives on inter-group conflict and bias and prosociality in the face of global emergencies. Third, the explanatory leverage of different sources of threats in terms of intra- and inter-group outcomes has unexplored heuristic potential. While most research approached the COVID-19 pandemic in terms of life threat, most likely different threat facets are connected to conflict and prosociality in ways that are so far unknown.

\section{Conclusion}

Our systematic review suggests that extant knowledge falls short of covering the broad spectrum of threats associated with the unprecedented COVD-19 pandemic. This knowledge gap is only partially addressed by recent empirical advances in the study of threat appraisals, as evidenced by the disproportionate scholarly focus on life threat and the scant attention for other more long-lasting or more contextual threats to the personal and social self 
and to group survival and social cohesion. As suggested by our review, more comprehensive research effort should encourage situated and contextual approaches, shedding more light on the vastly unequal psychological impact of the COVID-19 pandemic. Relatedly, research addressing intra- and inter-group outcomes in the face of pandemics or disasters should incorporate a broader conceptualization of threat appraisals to enhance our understanding of threat regulation. Rather than quantifying threat as a one-dimensional construct, it is essential to disentangle the dynamic configurations of multiple threats at the intra-individual, intragroup and inter-group level for a proper understanding of their contingent consequences.

The under-representation of perspectives from ethno-racial and immigrant minorities in the study of threat appraisals and consequences in response to the pandemic is another important gap evidenced by our systematic literature review. Not only does threat intensity seem to be quantitatively greater amongst the members of various minorities, but the scope of concern also seems to be qualitatively distinct in part and more diverse. Studying perspectives from ethno-racial and immigrant minorities is crucial to identify distinct threats and challenges to promote inclusive recovery plans and policies. Our call resonates with a more general critique of the continuing predominance of people from Western, educated, industrialized, rich and democratic (WEIRD) societies in psychology research (e.g., Muthukrishna et al., 2020). This imbalance has sustained a tendency to decontextualize psychological processes and to overlook perspectives from subordinate groups and cultures across the globe, thus hampering the potential social impact of psychological research in response to global societal challenges. To advance evidence-informed understandings and policies with a view to address stark inequalities in exposure, experience and outcomes of the pandemic, it seems essential to value the diversity of populations of interest, while considering participative approaches to actively involve underrepresented groups in the 
COVID-19 THREAT APPRAISALS FROM AN INTER-GROUP PERSPECTIVE

research process. By better representing diversity of viewpoints, research would better identify ways of living and coping cohesively with unprecedented challenges. 


\section{References}

Abedi, V., Olulana, O., Avula, V., Chaudhary, D., Khan, A., Shahjouei, S., Li, J., \& Zand, R. (2020). Racial, economic, and health inequality and COVID-19 infection in the United States. Journal of Racial and Ethnic Health Disparities. https://doi.org/10.1007/s40615020-00833-4

Ahorsu, D. K., Lin, C. Y., Imani, V., Saffari, M., Griffiths, M. D., \& Pakpour, A. H. (2020). The Fear of COVID-19 Scale: Development and initial validation. International Journal of Mental Health and Addiction. https://doi.org/10.1007/s11469-020-00270-8

Anderson, J., Lueders, A., Sankaran, S., Green, E., \& Politi, E. (2021, July 21). The COVID19 Multifaceted Threat Scale. https://doi.org/10.31234/osf.io/jfgvr

Anderson-Carpenter, K. D., \& Neal, Z. P. (2021). Racial disparities in COVID-19 impacts in Michigan, USA. Journal of Racial and Ethnic Health Disparities. https://doi.org/10.1007/s40615-020-00939-9

Andrighetto, L., Vezzali, L., Bergamini, G., Nadi, C., \& Giovannini, D. (2016). Inside the earthquake: Perceived disaster exposure and helping intentions among Italian and immigrant victims of the 2012 Italian earthquakes. Group Processes and Intergroup Relations, 19, 753-768. https://doi.org/10.1177/1368430215591040

Arpaci, I., Karataş, K., \& Baloğlu, M. (2020). The development and initial tests for the psychometric properties of the COVID-19 Phobia Scale (C19P-S). Personality and Individual Differences, 164. https://doi.org/10.1016/j.paid.2020.110108

Asbrock, F., \& Fritsche, I. (2013). Authoritarian reactions to terrorist threat: Who is being threatened, the me or the We? International Journal of Psychology, 48, 35-49. https://doi.org/10.1080/00207594.2012.695075

Branscombe, N. R., Ellemers, N., Spears, R., \& Doosje, B. (1999). The context and content of social identity threat. In N. Ellemers, R. Spears, \& B. Doosje (Eds.), Social identity: Context, commitment, content (pp. 35-58). Blackwell.

Brown, R. L., Richman, J. A., Moody, M. D., \& Rospenda, K. M. (2019). Alcohol-related effects of POST-9/11 discrimination in the context of the great recession: Race/ethnic variation. Addictive Behaviors, 93, 154-157. https://doi.org/10.1016/j.addbeh.2019.01.019

Chen, A. C. C., Keith, V. M., Airriess, C., Wei, L., \& Leong, K. J. (2007). Economic vulnerability, discrimination, and hurricane Katrina: Health among black Katrina survivors in Eastern New Orleans. Journal of the American Psychiatric Nurses Association, 13, 257-266. https://doi.org/10.1177/1078390307307260

Coelho, C. M., Suttiwan, P., Arato, N., \& Zsido, A. N. (2020). On the nature of fear and anxiety triggered by COVID-19. Frontiers in Psychology. https://doi.org/10.3389/fpsyg.2020.581314

Crabtree, A. (2013). Questioning psychosocial resilience after flooding and the consequences for disaster risk reduction. Social Indicators Research, 113, 711-728.

https://doi.org/10.1007/s11205-013-0297-8

Dhanani, L. Y., \& Franz, B. (2021). Why public health framing matters: An experimental study of the effects of COVID-19 framing on prejudice and xenophobia in the United States. Social Science and Medicine. https://doi.org/10.1016/j.socscimed.2020.113572

Demirtaş-Madran, H. A. (2020). Exploring the motivation behind discrimination and stigmatization related to COVID-19: A social psychological discussion based on the main theoretical explanations. Frontiers in Psychology, 11.

https://doi.org/10.3389/fpsyg.2020.569528 
Doise, W. (1986). Levels of explanation in social psychology. Cambridge University Press.

Dougall, A. L., Herberman, H. B., Delahanty, D. L., Inslicht, S. S., \& Baum, A. (2000). Similarity of prior trauma exposure as a determinant of chronic stress responding to an airline disaster. Journal of Consulting and Clinical Psychology, 68, 290-295. https://doi.org/10.1037/0022-006X.68.2.290

Drury, J., Cocking, C., \& Reicher, S. (2009). Everyone for themselves? A comparative study of crowd solidarity among emergency survivors. British Journal of Social Psychology, 48, 487-506. https://doi.org/10.1348/014466608X357893

Durkheim, E. (1897/1987). Suicide (J. A. Spaulding \& G. Simpson, Trans.). London, UK: Routledge \& Kegan Paul

ECDC. (2020). Rapid risk assessment: Coronavirus disease 2019 (COVID-19) in the EU/EEA and the UK - tenth update. https://www.ecdc.europa.eu/en/publicationsdata/rapid-risk-assessment-coronavirus-disease-2019-covid-19-pandemic-tenth-update

Elisabeth, M., Maneesh, P. S., \& Michael, S. (2020). Refugees in Sweden during the Covid19 pandemic - The need for a new perspective on health and integration. Frontiers in Public Health, 8, 6-10. https://doi.org/10.3389/fpubh.2020.574334

Fairlamb, S., \& Cinnirella, M. (2021). To be or not to be tolerant? A Terror Management perspective exploring the ideological dilemma of tolerance and prejudice. British Journal of Social Psychology, 60, 360-382. https://doi.org/10.1111/bjso.12407

Feng, L., Dong, Z. jiao, Yan, R. yu, Wu, X. qian, Zhang, L., Ma, J., \& Zeng, Y. (2020). Psychological distress in the shadow of the COVID-19 pandemic: Preliminary development of an assessment scale. Psychiatry Research. https://doi.org/10.1016/j.psychres.2020.113202

Fergusson, D. M., Boden, J. M., Horwood, L. J., \& Mulder, R. T. (2015). Perceptions of distress and positive consequences following exposure to a major disaster amongst a well-studied cohort. Australian \& New Zealand Journal of Psychiatry, 49, 351-359. https://doi.org/10.1177/0004867414560652

Golec de Zavala, A., Bierwiaczonek, K., Baran, T., Keenan, O., \& Hase, A. (2020). The COVID-19 pandemic, authoritarianism, and rejection of sexual dissenters in Poland. Psychology of Sexual Orientation and Gender Diversity. https://doi.org/10.1037/sgd0000446

Gonzales, R. G., Suárez-Orozco, C., \& Dedios-Sanguineti, M. C. (2013). No place to belong: Contextualizing concepts of mental health among undocumented immigrant youth in the United States. American Behavioral Scientist, 57, 1174-1199.

https://doi.org/10.1177/0002764213487349

Green, E. G. T., Krings, F., Staerklé, C., Bangerter, A., Clémence, A., Wagner-Egger, P., \& Bornand, T. (2010). Keeping the vermin out: Perceived disease threat and ideological orientations as predictors of exclusionary immigration attitudes. Journal of Community \& Applied Social Psychology, 20, 299-316. https://doi.org/10.1002/casp.1037

Greysen, S. R., Horwitz, L. I., Covinsky, K. E., Gordon, K., Ohl, M. E., \& Justice, A. C. (2013). Does social isolation predict hospitalization and mortality among HIV+ and uninfected older veterans? Journal of the American Geriatrics Society, 61, 1456-1463. https://doi.org/10.1111/jgs.12410

Guerra, C., Cumsille, P., \& Martínez, M. L. (2014). Post-traumatic stress symptoms in adolescents exposed to an earthquake: Association with self-efficacy, perceived magnitude, and fear. International Journal of Clinical and Health Psychology, 14, 202207. https://doi.org/10.1016/j.ijchp.2014.05.001 
Heir, T., Blix, I., \& Knatten, C. K. (2016). Thinking that one's life was in danger: Perceived life threat in individuals directly or indirectly exposed to terror. British Journal of Psychiatry, 209, 306-310. https://doi.org/10.1192/bjp.bp.115.170167

Hossain, M. M., Sultana, A., \& Purohit, N. (2020). Mental health outcomes of quarantine and isolation for infection prevention: a systematic umbrella review of the global evidence. Epidemiology and Health, 42. https://doi.org/10.4178/epih.e2020038

Irshad, M., Khattak, S. A., Hassan, M. M., Majeed, M., \& Bashir, S. (2020). How perceived threat of Covid-19 causes turnover intention among Pakistani nurses: A moderation and mediation analysis. International Journal of Mental Health Nursing. https://doi.org/10.1111/inm.12775

Jonas, E., McGregor, I., Klackl, J., Agroskin, D., Fritsche, I., Holbrook, C., Nash, K., Proulx, T., \& Quirin, M. (2014). Threat and defense. From anxiety to approach. In Advances in Experimental Social Psychology (Vol. 49). Elsevier. https://doi.org/10.1016/B978-0-12800052-6.00004-4

Kachanoff, F., Bigman, Y. E., Kapsaskis, K., \& Gray, K. (2020). Measuring realistic and symbolic threat of COVID-19 and their unique impact on well-being and adherence to public health behaviors. Social Psychological and Personality Science, 53. https://doi.org/10.1017/CBO9781107415324.004

Kalengayi, F. K. N., Hurtig, A. K., Ahlm, C., \& Krantz, I. (2012). Fear of deportation may limit legal immigrants' access to HIV/AIDS-related care: A survey of Swedish language school students in Northern Sweden. Journal of Immigrant and Minority Health, 14, 3947. https://doi.org/10.1007/s10903-011-9509-y

Kim, M., \& Chang, H. (2014). An investigation of Korean children's prejudicial attitudes toward a national tragedy in Japan. Journal of Moral Education, 43, 282-301. https://doi.org/10.1080/03057240.2014.920307

Kinzie, J. D. (2008). Some of the effects of terrorism on refugees. Journal of Aggression, Maltreatment \& Trauma, 9, 411-420. https://doi.org/10.1300/J146v09n03_12

Kira, I. A., Shuwiekh, H. A. M., Alhuwailah, A., Ashby, J. S., Sous Fahmy Sous, M., Baali, S. B. A., Azdaou, C., Oliemat, E. M., \& Jamil, H. J. (2020). The effects of COVID-19 and collective identity trauma (intersectional discrimination) on social status and wellbeing. Traumatology. https://doi.org/10.1037/trm0000289

Kira, I. A., Shuwiekh, H. A. M., Rice, K. G., Ashby, J. S., Elwakeel, S. A., Sous, M. S. F., Alhuwailah, A., Baali, S. B. A., Azdaou, C., Oliemat, E. M., \& Jamil, H. J. (2020). Measuring COVID-19 as Traumatic Stress: Initial Psychometrics and Validation. Journal of Loss and Trauma, 1-18. https://doi.org/10.1080/15325024.2020.1790160

Major, B., \& O'Brien, L. T. (2005). The social psychology of stigma. Annual Review of Psychology, 56, 393-421. https://doi.org/10.1146/annurev.psych.56.091103.070137

Mani, A., Mullainathan, S., Shafir, E., \& Zhao, J. (2013). Poverty impedes cognitive function. Science, 342, 976-981. https://doi.org/10.1126/science.1246799

Marinucci, M., \& Riva, P. (2020). Surrendering to social emptiness: Chronic social exclusion longitudinally predicts resignation in asylum seekers. British Journal of Social Psychology. https://doi.org/10.1111/bjso.12410

Martiniello, M., \& Rea, A. (2014). The concept of migratory careers: Elements for a new theoretical perspective of contemporary human mobility. Current Sociology, 62, 10791096. https://doi.org/10.1177/0011392114553386

McFarlane, A. C. (2010). The long-term costs of traumatic stress: Intertwined physical and psychological consequences. World Psychiatry, 9, 3-10. https://doi.org/10.1002/j.2051- 


\subsection{0.tb00254.x}

Marques, J. M., Abrams, D., Paez, D., \& Martinez-Taboada, C. (1998). The role of categorization and in-group norms in judgments of groups and their members. Journal of Personality and Social Psychology, 75, 976-988. https://doi.org/10.1037/00223514.75.4.976

Mertens, G., Duijndam, S., Smeets, T., \& Lodder, P. (2021). The latent and item structure of COVID-19 fear: A comparison of four COVID-19 fear questionnaires using SEM and network analyses. Journal of Anxiety Disorders, 81. https://doi.org/10.1016/j.janxdis.2021.102415

Moher, D., Liberati, A., Tetzlaff, J., Altman, D. G., Altman, D., Antes, G., Atkins, D., Barbour, V., Barrowman, N., Berlin, J. A., Clark, J., Clarke, M., Cook, D., D’Amico, R., Deeks, J. J., Devereaux, P. J., Dickersin, K., Egger, M., Ernst, E., ... Tugwell, P. (2009). Preferred reporting items for systematic reviews and meta-analyses: The PRISMA statement. PLoS Medicine, 6. https://doi.org/10.1371/journal.pmed.1000097

Mullainathan, S., \& Shafir, E. (2014). Scarcity: The true cost of not having enough. Penguin. Muthukrishna, M., Bell, A. V., Henrich, J., Curtin, C. M., Gedranovich, A., McInerney, J., \& Thue, B. (2020). Beyond Western, Educated, Industrial, Rich, and Democratic (WEIRD) psychology: Measuring and mapping scales of cultural and psychological distance. Psychological Science, 31, 678-701. https://doi.org/10.1177/0956797620916782

Nisa, C. F., Bélanger, J. J., Faller, D. G., Buttrick, N. R., Mierau, J. O., Austin, M. M. K., Schumpe, B. M., Sasin, E. M., Agostini, M., Gützkow, B., Kreienkamp, J., Abakoumkin, G., Abdul Khaiyom, J. H., Ahmedi, V., Akkas, H., Almenara, C. A., Atta, M., Bagci, S. C., Basel, S., ... Leander, N. P. (2021). Lives versus livelihoods? Perceived economic risk has a stronger association with support for COVID-19 preventive measures than perceived health risk. Scientific Reports, 11. https://doi.org/10.1038/s41598-021-88314-4

Oswald, D. L. (2005). Understanding anti-Arab reactions post-9/11: The role of threats, social categories, and personal ideologies. Journal of Applied Social Psychology, 35, 1775-1799. https://doi.org/10.1111/j.1559-1816.2005.tb02195.x

Piwowarczyk, L. A., \& Keane, T. M. (2007). Impact of September 11 on refugees and those seeking asylum. Transcultural Psychiatry, 44, 566-580. https://doi.org/10.1177/1363461507083897

Politi, E., \& Roblain, A. (2021). Refugee committee: Moving beyond the COVID-19 outbreak. https://doi.org/10.13140/RG.2.2.35224.11521

Politi, E., Van Assche, J., Caprara, G. V., \& Phalet, K. (2020). No man is an island: Psychological underpinnings of prosociality in the midst of the COVID-19 outbreak. Personality and Individual Differences. https://doi.org/10.1016/j.paid.2020.110534

Rathbone, J., Hoffmann, T., \& Glasziou, P. (2015). Faster title and abstract screening? Evaluating Abstrackr, a semi-automated online screening program for systematic reviewers. Systematic Reviews, 4, 1-7. https://doi.org/10.1186/s13643-015-0067-6

Ritchie, L. A. (2012). Individual stress, collective trauma, and social capital in the wake of the Exxon valdez oil spill. Sociological Inquiry, 82, 187-211.

https://doi.org/10.1111/j.1475-682X.2012.00416.x

Rogers, A. H., Bogiaizian, D., Salazar, P. L., Solari, A., Garey, L., Fogle, B. M., Schmidt, N. B., \& Zvolensky, M. J. (2021). COVID-19 and anxiety sensitivity across two studies in Argentina: Associations with COVID-19 worry, symptom severity, anxiety, and 
functional impairment. Cognitive Therapy and Research. https://doi.org/10.1007/s10608-020-10194-1

Romero, M. (2008). Crossing the immigration and race border: A critical race theory approach to immigration studies. Contemporary Justice Reivew, 11, 23 -37. https://doi.org/10.1080/10282580701850371

Rousseau, C., Hassan, G., Moreau, N., \& Thombs, B. D. (2011). Perceived discrimination and its association with psychological distress among newly arrived immigrants before and after September 11, 2001. American Journal of Public Health, 101, 909-915. https://doi.org/10.2105/AJPH.2009.173062

Ryan, R. M., \& Deci, E. L. (2000). Self-determination theory and the facilitating of intrinsic motivation, social development, and well-being. American Psychologist, 55, 68-78. https://doi.org/10.1037110003-066X.55.1.68

Salyer, J. L. H., Walusimbi, M. L., \& Fitzpatrick, J. J. (2008). Knowledge and attitudes of Ugandan midwives regarding HIV. Journal of the Association of Nurses in AIDS Care, 19, 105-113. https://doi.org/10.1016/j.jana.2008.01.001

Sears, D. O., Sidanius, J., \& Bobo, L. (2000). Racialized politics: The debate about racism in America. University of Chicago Press.

Shalev, A. (2006). Psychological responses to continuous terror: A study of two communities in Israel. American Journal of Psychiatry, 163, 667. https://doi.org/10.1176/appi.ajp.163.4.667

Şimşir, Z., Koç, H., Seki, T., \& Griffiths, M. D. (2021). The relationship between fear of COVID-19 and mental health problems: A meta-analysis. Death Studies. https://doi.org/10.1080/07481187.2021.1889097

Sirin, S. R., \& Fine, M. (2007). Hyphenated selves: Muslim Aamerican youth negotiating identities on the fault lines of global conflict. Applied Developmental Science, 11, 151163. https://doi.org/10.1080/10888690701454658

Smid, G. E., Drogendijk, A. N., Knipscheer, J., Boelen, P. A., \& Kleber, R. J. (2018). Loss of loved ones or home due to a disaster: Effects over time on distress in immigrant ethnic minorities. Transcultural Psychiatry, 55, 648-668. https://doi.org/10.1177/1363461518784355

Stephan, W. G., Ybarra, O., \& Morrison, K. R. (2009). Handbook of prejudice, stereotyping, and discrimination. In T. D. Nelson (Ed.), Handbook of prejudice, stereotyping, and discrimination (pp. 43-60). Psychology Press.

Stutterheim, S. E., Shiripinda, I., Bos, A. E. R., Pryor, J. B., De Bruin, M., Nellen, J. F. J. B., Kok, G., Prins, J. M., \& Schaalma, H. P. (2011). HIV status disclosure among HIVpositive African and Afro-Caribbean people in the Netherlands. AIDS Care Psychological and Socio-Medical Aspects of AIDS/HIV, 23, 195-205. https://doi.org/10.1080/09540121.2010.498873

Tabri, N., Hollingshead, S. J., \& Wohl, M. J. A. (2020, March 31). Framing Covid-19 as an existential threat predicts anxious arousal and prejudice. https://doi.org/10.31234/osf.io/mpbtr

Taylor, S., Landry, C. A., Paluszek, M. M., Fergus, T. A., McKay, D., \& Asmundson, G. J. G. (2020). Development and initial validation of the COVID Stress Scales. Journal of Anxiety Disorders, 72(May), 102232. https://doi.org/10.1016/j.janxdis.2020.102232

Tedeschi, R. G., Park, C., \& Calhoun, L. G. (1998). Posttraumatic growth: Positive changes in the aftermath of crisis. Lawrence Erlbaum.

Teymoori, A., Bastian, B., \& Jetten, J. (2017). Towards a psychological analysis of anomie. 
Political Psychology, 38, 1009-1023. https://doi.org/10.1111/pops.12377

Tricco, A. C., Langlois, E. V., \& Straus, S. E. (2017). Rapid reviews to strengthen health policy and systems: A practical guide. In World Health Organisation. World Health Organisation.

Van Assche, J., Politi, E., Dessel, P. Van, \& Phalet, K. (2020). To punish or to assist? Divergent reactions to ingroup and outgroup members disobeying social distancing. British Journal of Social Psychology, 59, 594-606. https://doi.org/10.1111/bjso.12395

Van de Vyver, J., Houston, D. M., Abrams, D., \& Vasiljevic, M. (2016). Boosting belligerence: How the July 7, 2005, London bombings affected liberals' moral foundations and prejudice. Psychological Science, 27, 169-177. https://doi.org/10.1177/0956797615615584

Van Leeuwen, E. (2007). Restoring identity through outgroup helping: Beliefs about international aid in response to the December 2004 tsunami. European Journal of Social Psychology, 37, 661-671. https://doi.org/10.1002/ejsp.389

Vansteenkiste, M., \& Ryan, R. M. (2013). On psychological growth and vulnerability: basic psychological need satisfaction and need frustration as a unifying principle. Journal of psychotherapy integration, 23, 263-280. https://doi.org/10.1037/a0032359

Vezzali, L., Versari, A., Cadamuro, A., Trifiletti, E., \& Di Bernardo, G. A. (2018). Out-group threats and distress as antecedents of common in-group identity among majority and minority group members in the aftermath of a natural disaster. International Journal of Psychology, 53, 417-425. https://doi.org/10.1002/ijop.12406

Vollhardt, J. R., \& Staub, E. (2011). Inclusive altruism born of suffering: The relationship between adversity and prosocial attitudes and behavior toward disadvantaged outgroups. American Journal of Orthopsychiatry, 81, 307-315. https://doi.org/10.1111/j.19390025.2011.01099.x

Vuori, M. (2016). Revisiting local responses to mass violence. Journal of Risk Research, 19, 515-532. https://doi.org/10.1080/13669877.2014.1003317

WHO. (2020). Apart together survey: Preliminary overview of refugees and migrants selfreported impact of COVID-19. https://reliefweb.int/report/world/aparttogether-surveypreliminary-overview-refugees-and-migrants-self-reported-impact

Wu, C., Qian, Y., \& Wilkes, R. (2021). Anti-Asian discrimination and the Asian-white mental health gap during COVID-19. Ethnic and Racial Studies, 44, 819-835. https://doi.org/10.1080/01419870.2020.1851739

Yako, R. M., \& Biswas, B. (2014). "We came to this country for the future of our children. We have no future": Acculturative stress among Iraqi refugees in the United States. International Journal of Intercultural Relations, 38, 133-141. https://doi.org/10.1016/j.ijintrel.2013.08.003

Zagefka, H. (2021). Intergroup helping during the coronavirus crisis: Effects of group identification, ingroup blame and third-party outgroup blame. Journal of Community and Applied Social Psychology, 31, 83-93. https://doi.org/10.1002/casp.2487

Zeppegno, P., Gramaglia, C., Guerriero, C., Madeddu, F., \& Calati, R. (2020, May 17). Lessons learnt from China and call for timely crisis Interventions in Italy. https://doi.org/10.31234/osf.io/z26 
COVID-19 THREAT APPRAISALS FROM AN INTER-GROUP PERSPECTIVE

\section{Table 1.}

Concepts and Terms used in the Search Strategies.

\begin{tabular}{llll}
\hline \multicolumn{1}{c}{$\begin{array}{c}\text { Constant Concept: Threat } \\
\text { context }\end{array}$} & \multicolumn{1}{c}{$\begin{array}{c}\text { Variable concept 1: } \\
\text { Individual threats }\end{array}$} & $\begin{array}{c}\text { Variable concept 2: } \\
\text { Collective threats }\end{array}$ & $\begin{array}{l}\text { Variable concept 3: Intra- } \\
\text { and inter-group outcomes }\end{array}$ \\
\hline natural disaster OR & uncertainty OR & symbolic threat OR & ostracism OR \\
infectious disease OR & threat OR & realistic threat OR & scapegoat OR \\
pandemic OR & fear OR & collective threat OR & discrimination OR \\
terrorism OR & basic needs OR & intergroup threat OR & stigmatisation OR \\
COVID-19 & self-determination & group cohesion OR & intergroup conflict OR \\
& group survival OR & outgroup derogation OR \\
& group integrity & prosociality OR \\
& & solidarity OR \\
& & intergroup helping OR \\
& & altruism OR \\
& & empathy OR
\end{tabular}

Notes: Three searches were conducted; each used the constant concept and one of the variables concepts.

Specifically, the threat context was used with variables concepts to target individual-level threats (Search 1), collective-level threats (Search 2) or intra- and inter-group outcomes (Search 3). 


\section{COVID-19 THREAT APPRAISALS FROM AN INTER-GROUP PERSPECTIVE}

\section{Figure 1.}

Flowchart for study selection process, concepts, and terms used in the search strategies

Published records identified through database searching $(n=4,349)$

Search 1: Individual threats $(n=3,337)$

Search 2: Collective threats $(n=84)$

Search 3: Intra- and inter-group outcomes $(n=928)$

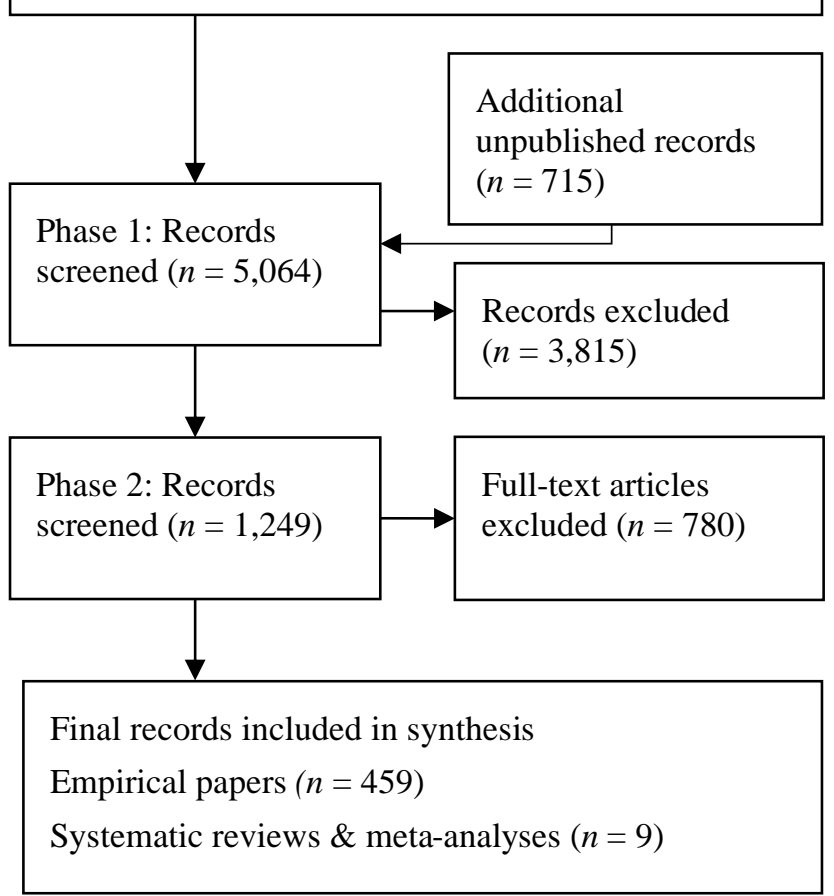

Note: Three searches were conducted, each using the constant concept and the none of the variables concepts. Specifically, the threat context was used with variable concepts to target individual-level threats (Search 1), collective-level threats (Search 2) or intra- and inter-group outcomes (Search 3). Phase 1 of screening involved assessing for potential suitability using an automated process (Tricco et al., 2017). Phase 2 of screening involved assessing eligibility for inclusion based on the full-text of the article 
Figure 2.

Empirical studies extracted from literature review and organized as a function of general and ethno-racial-immigrant-specific threat appraisals

General threats

reported by both majority and ethno-racial and immigrant minorities

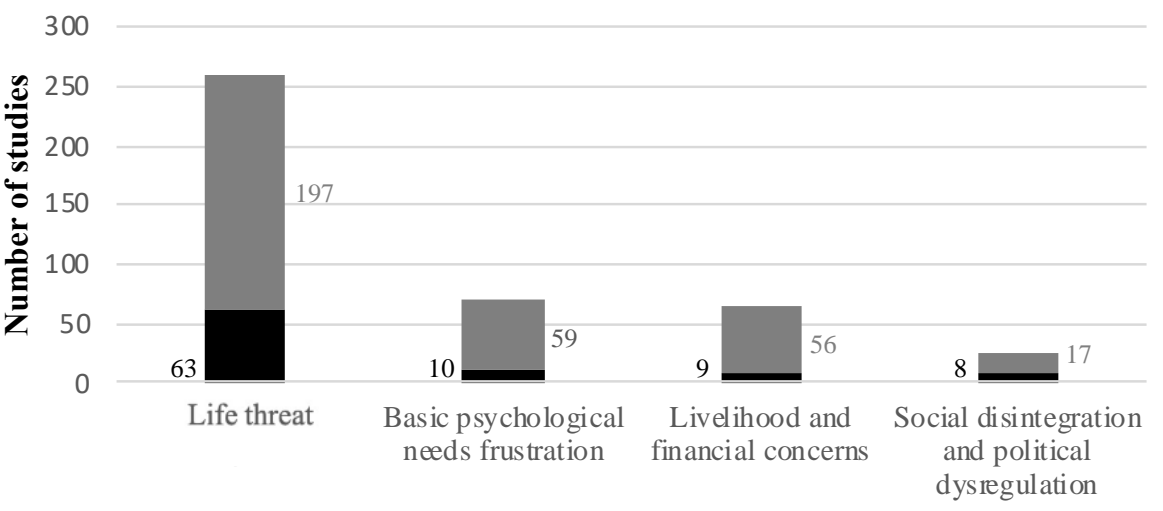

Specific threats

reported uniquely by ethno-racial and immigrant minorities

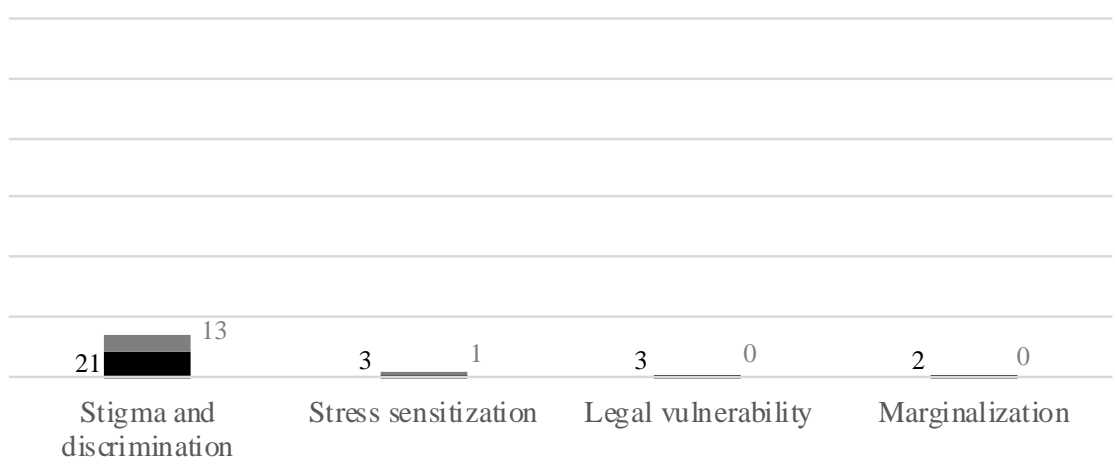

- Previous disasters and pandemics

- Current COVID-19 outbreak

Note: Frequencies pertaining to previous disasters and pandemics are reported in black on the bottom left, whereas frequencies pertaining to the current COVID-19 outbreak are reported in grey on the top right of each histogram. Systematic reviews and meta-analyses were not included in the graph. Because many studies focused on several types of threats in parallel, the total count exceeds the number of studies retained. For the sake of readability, generic threats are not reported separately for the majority population and ethno-racial and immigrant minorities. For more details, see Table S1 in ESM. 